\title{
NEW IDEA FOR THE WELD BETWEEN ORTHOTROPIC DECK AND U RIB
}

\author{
Changjiang Wang ${ }^{1, a}$, Yuling Zhang ${ }^{2, b,{ }^{*}}$, Xiangyang Chen ${ }^{1, \mathrm{c}}$, Jian $\mathrm{Yao}^{2, \mathrm{~d}}$ and \\ Zifang Ren ${ }^{3, \mathrm{e}}$ \\ ${ }^{1}$ Zhejiang Provincial Institute of Communications Planning, Design \& Research, Hangzhou, CHINA \\ ${ }^{2}$ College of Urban Construction, Zhejiang Shuren University, Zhejiang Hangzhou, CHINA \\ ${ }^{3}$ Beijing Baishan heavy industry co., LTD, Beijing, CHINA \\ a1299522116@qq.com, b1299522116@qq.com, c1299522116@qq.com, dyaojian5803@qq.com, \\ e1299522116@qq.com,
}

Keywords: Steel bridge, Manufacturing technology, Thicken edge U rib, Fatigue life

Abstract. Orthotropic steel bridge deck system has a large number of applications in recent years in many countries. Based on the research on the Thicken Edge U rib (TEU), a new fatigue control technology route is put forward in this paper. The conception is that, on the premise of increasing a small amount of material to increase the weld dimension, so as to reduce the fatigue stress range in the weld, until transfer the fatigue control section from the weld to the base material of $U$ rib. Because the fatigue resistance for the base material is much higher than that for the weld, hence, it is expected to completely solve the fatigue cracking problems in the weld of longitudinal ribs connected with steel bridge deck.

\section{Introduction}

Using less material, orthotropic steel bridge deck structure can get higher strength, and the overall and local stiffness. Compared with the traditional bridge, it reduces $20 \% \sim 40 \%$ in weight ${ }^{[1,2]}$ (Wolchuk 1999; Lyse and Madsen 1938). It is the reason why the orthotropic deck is widely used in all kinds of bridges, including the long-span suspension bridge and cable-stayed bridge. The orthotropic steel bridge deck replaced the original reinforced concrete bridge deck in 1985 in the United States during the reinforcement of Golden Gate Bridge that was completed in 1937, which shows the effective function of the orthotropic steel bridge deck structure in the maintenance of old bridge.

Orthotropic steel bridge deck structure produced structural cracks in succession after a large number of use, which is given priority to with fatigue crack. According to the nature of the problem, it can be traced back to three reasons. The first is that there was no enough attention to the fatigue problems of this kind of structure early. The design calculation was focused only on the static strength and the excessive pursuit of material saving. As a result, the thickness of the steel bridge deck and rib plate is too thin, and the height of the longitudinal rib is short (less than $12 \mathrm{~mm}$ thickness of deck and $7 \mathrm{~mm}$ of $U$ rib; less than $250 \mathrm{~mm}$ height of $U$ rib). In addition, the longitudinal rib is also of the structural defects without continuous through cross rib. The second aspect is reflected in the understanding of structural details. First the longitudinal ribs and steel bridge deck is connected with no penetration fillet weld, then excessive pursuit of weld penetration completely, making the undercut welding defects in the deck; the unreasonable structural defects in shape and size on cross rib passed through by longitudinal rib continuously. Combined with the welding construction quality control is lax (especially the site overhead welding by hand), etc.. All of them give adverse impact. Third aspect reflects on the insufficient forecasting of fatigue load. The design give the disconnect estimates with the growth of the late heavy truck, the actual excess heavy vehicle, and overload vehicles. As shown of Figure 1, They are the pictures of cracking on orthotropic steel bridge deck structure of a long-span bridge built in 1990s. 


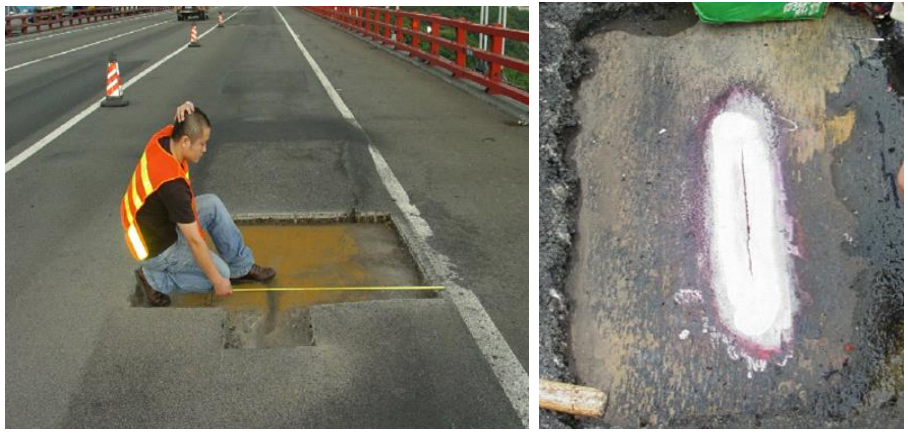

(a)Longitudinal cracks seriously

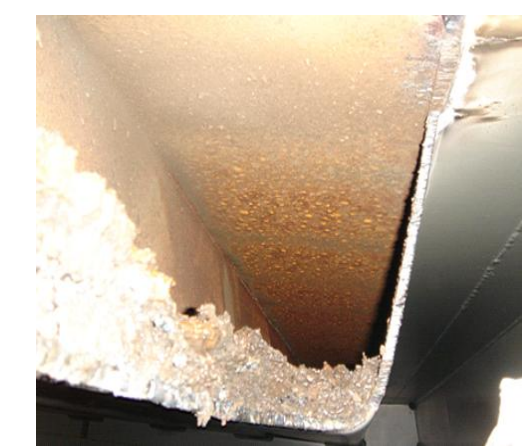

(b) fragments fall into internal U rib

Figure 1 crack in orthotropic steel bridge deck and the longitudinal weld connection

Through a large number of experimental study, Dr. John w. Fisher pointed out in many occasions that, the orthotropic steel bridge deck is most likely the bridge structure to provide services in 100 years cycles $^{[3,4,5]}$ (Tsakopoulos, Fisher and Hon 2003; Bocchieri and Fisher 1998; Tsakopoulos and Fisher 2005). Since the $1980 \mathrm{~s}$, British transport and road research trials institute (TRRL), the European railway research institute (ERRI), and the research institutes of the United States and Japan have a series research, to have had a relatively clear understanding about the above, and the basic ideas embodied in later European standard ${ }^{[6]}$ (EN 2006) and AASHTO specifications ${ }^{[7]}$ (AAASHTO 2012) of the United States.

In the study of the orthotropic steel bridge deck structure, steel bridge deck and longitudinal connection is one of the most studied of weld seam, the reason is:

(1) In a typical orthotropic bridge deck, the length of weld connection between longitudinal ribs and the deck is 50 times of bridge length or more, depending on the number of longitudinal rib on cross section. So the weld becomes very important not only for manufacturing costs, but also for the long-term performance of control.

(2) Once cracking, the connection part will directly damage to bridge deck pavement, increase the stress concentration phenomenon and structure degradation. At the same time, it will induce the inefficiency of the dehumidification system in the steel cabinet, to cause the corrosion in a wider range of components.

(3) The robustness of the longitudinal weld is directly related to the service life of the bridge deck pavement and the driving safety. So it has a high social awareness. In addition, to maintain and repair the area is bound to affect the traffic, the maintenance is difficult.

So far, there is no solution that is very satisfied. In view of the longitudinal connection weld between steel bridge deck and rib, based on the analysis on its mechanical characteristics, this paper study constructive structure design scheme to solve the fatigue crack resistance fundamentally.

\section{Review of Related Research on Connection between Deck and Ribs}

The connection between the steel bridge deck and longitudinal ribs experienced a riveting, intermittent weld ${ }^{[2]}$ (Wolchuk 1999) to the continuous fillet welds ${ }^{[1]}$ (Lyse and Madsen 1938). In recent years, research work mainly focus on the improvement of structural details, seeking more accurate calculation method and testing technology, etc.. In the improvement of detail, in addition to research deeply on the reasonable weld penetration depth ${ }^{[8]}$ (Sim, Uang and Sikorsky 2008), stable welding quality is controlled by manufacturing automation and robotics to reduce artificial factors influence, which is represented by Hong Kong-Zhuhai-Macao Bridge ${ }^{[9]}$ (Zhiguo, Junping, Liang and Ping 2014). In aspect of reducing the orthotropic deck stress and deformation, some new type of pavement on the bridge deck is used as one of the improving measures ${ }^{[10]}$ (Feng 2004). Furthermore, put stiffener inside of the longitudinal rib ${ }^{[11]}$ (Huating, Xiaoqi and Yan 2012). Those researches have a good effect. In aspect of Looking for more accurate analysis method to calculate fatigue, there are calculation method research of steel box girder bridge structure ${ }^{[12]}$ (Yanni 2011), residual stress numerical simulation for longitudinal weld between steel bridge deck and rib $^{[13]}$ (Xing, Xiuxing, Su 
and Kefu 2014), the impact research on the fatigue stress amplitude produced by transverse distribution of the wheel track ${ }^{[14]}$ (Bing, Chong, Wenjun and Yuqiang 2010), fatigue long crack extension research under the action of bending outside surface ${ }^{[15]}$ (Liang, Liji, Gao and Wenming 2012), study on calculation method of detail tectonic stress in orthotropic deck ${ }^{[16]}$ (Bo, Hongxing, Liqiang, Hao and Tong 2008), etc.. In aspect of looking for more accurate detection technology, researchers try to use the ultrasonic phased array method to detect the depth of longitudinal fillet weld penetration in U-shaped rib ${ }^{[17]}$ (Gang and Kaibin 2013). In order to play advantage of orthotropic steel bridge deck, the literature ${ }^{[18]}$ (BRIGHT and SMITH 2004) put forward the new concept of orthotropic steel bridge deck structure design. Its main idea is to work alternative I-shaped girder as longitudinal ribs, increase the lower plate, finish weld work by laser welding technology to connect I beam flange up and down, in order to reach the purpose of reducing longitudinal welding stress, as shown in Figure 2. The design idea develops the train of thought for the researchers.

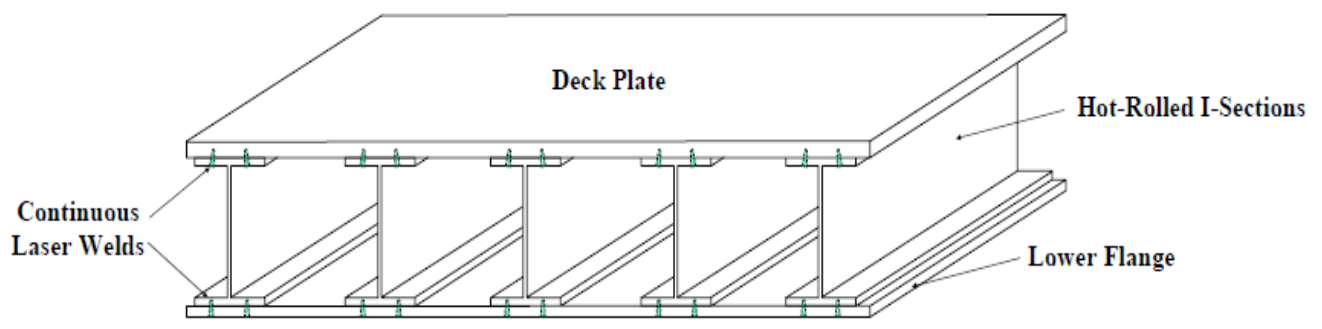

Figure 2 closed "sandwich" steel bridge deck

Analysis of the above research results, the authors think it is currently needed that, through some simple changes, on the basis of the existing processing technology, to get the purpose never produce fatigue crack on the weld connected between steel bridge deck and the longitudinal rib.

\section{Cause Analysis of Longitudinal Crack in Steel Bridge Deck}

Calculation and analysis ${ }^{[19]}$ (Xiaoguang and Yuling 2008) show that the stress in the orthotropic deck is small under the action of the whole bridge load. The main causes occurring fatigue crack are the local stress of wheel load.

The fatigue result of the longitudinal weld connection between the steel bridge deck and U-shaped rib is longitudinal crack of steel bridge deck, as shown in Figure 3.

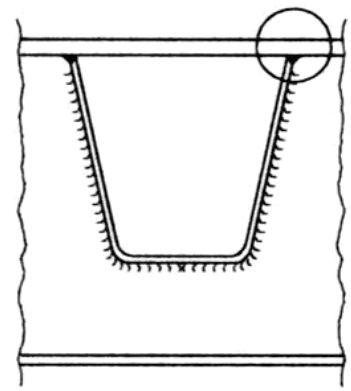

(a)weld position

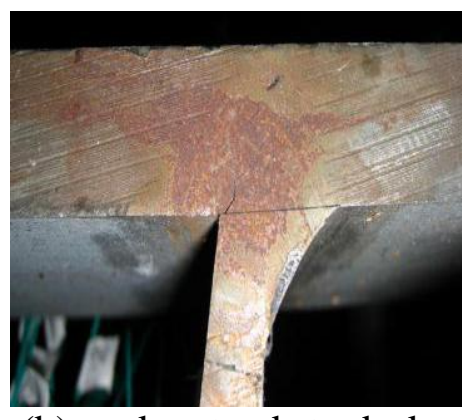

(b)crack extends to deck

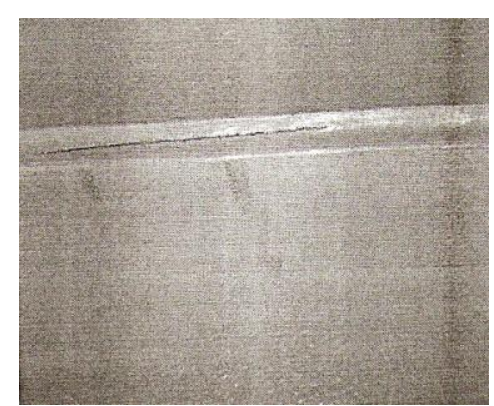

(c) real bridge longitudinal crack

Figure 3 longitudinal seam connected bridge deck with U-shaped rib and the crack initiation

The longitudinal cracks are caused mainly by the repeated stresses of the relative angle change between bridge deck and rib plate under vertical deformation of bridge deck at transverse somewhere outside weld with wheel load. The weld has the bending tensile stress, as shown in Figure 4. 


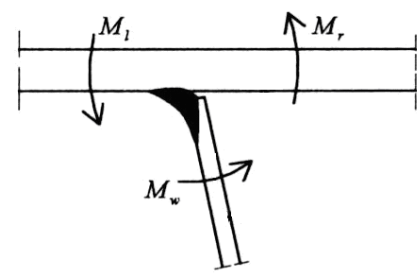

(a) case 1

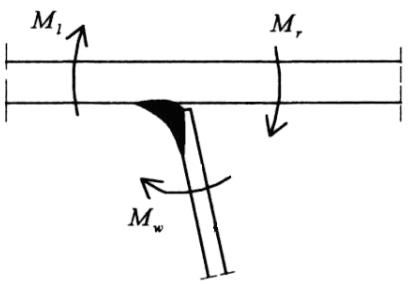

(b) case 2

Figure 4 stress analysis of longitudinal weld connected steel bridge deck with U-shaped rib

In case 1 of Figure 4, it is seen clearly that the tension side of the weld is the root of the weld, where the weld surface is the nature welding state. So long as its shape is not good, its fatigue strength is very low. The tension side in case 2 is on another side of weld that affects generally less than in case 1. The external load value and the distribution on the bridge deck have a lot to do with the stress in the weld. For railway bridges, load acts directly on the rail, again by the sleeper distribution to the bridge, so the deck loading position is relatively fixed, the consideration case is only the bending moment applying wheel load at specific parts from the weld. For highway bridges, car loads have strong randomness. It is necessary to consider all possible adverse working condition of loading position.

\section{U-shaped Longitudinal Rib Design With Anti-fatigue Structure}

\section{Main Technical Route}

Highway bridge operation vehicles have a strong randomness. Combined with the actual heavy truck, the longitudinal weld is subjected to high bending stress frequently. It is of great significance to improve the fatigue life of the weld. At present there are two kinds of general practice. One is reduce the longitudinal rib stress from wheel load by increasing the deck stiffness. The second is to improve the longitudinal seam welding quality to improve its fatigue performance. Based on the research on the Thicken Edge U rib (TEU), a new fatigue control technology route is put forward in this paper. The conception is that, on the premise of increasing a small amount of material to increase the weld dimension, so as to reduce the fatigue stress range in the weld, until transfer the fatigue control section from the weld to the base material of $U$ rib. Because the fatigue resistance for the base material is much higher than that for the weld, hence, there is the possibility to solve the fatigue cracking problems in the weld of longitudinal ribs connected with steel bridge deck. The method to implement it is to increase longitudinal weld cross sectional area connected $U$ rib with deck by hot extrusion process, to reduce the fatigue stress of $U$ rib weld beneath the base material. This technical route is easy to implement, the costs are relatively low, and the effect is remarkable.

\section{Structural Scheme Design Research}

Preliminary Scheme for TEU. On the basis of a large number of structural analysis and calculation by Zhejiang Provincial Institute of Communications Planning, Design \& Research and Beijing Baishan heavy industry co., LTD., etc., the preliminary section of TEU is put forward. The specific size is shown in Figure 5.
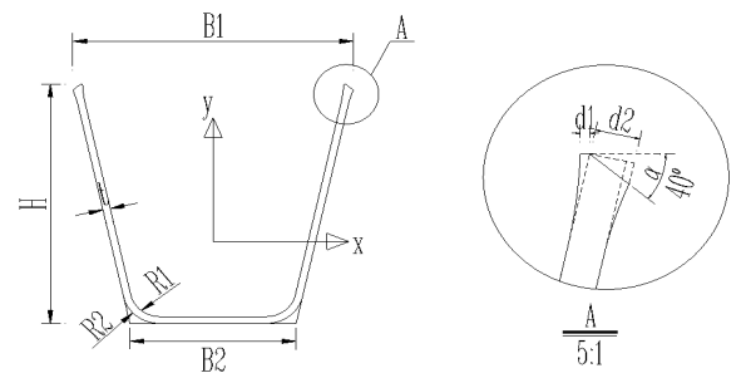

Figure 5 preliminary design for TEU section

In Figure 5, when the thickness of $U$ rib $t=8 \mathrm{~mm}$, preliminary design $\mathrm{d}_{1}=2 \mathrm{~mm}, \mathrm{~d}_{2}=10 \mathrm{~mm}$. 
Processing and Manufacturing for Thickening $\mathbf{U}$ rib base. Some relevant unit has carried out a series of hot extrusion and cold extrusion forming for TEU processing production equipment and technology research. At present already have the product ability for TEU. Its product is shown in Figure 6.
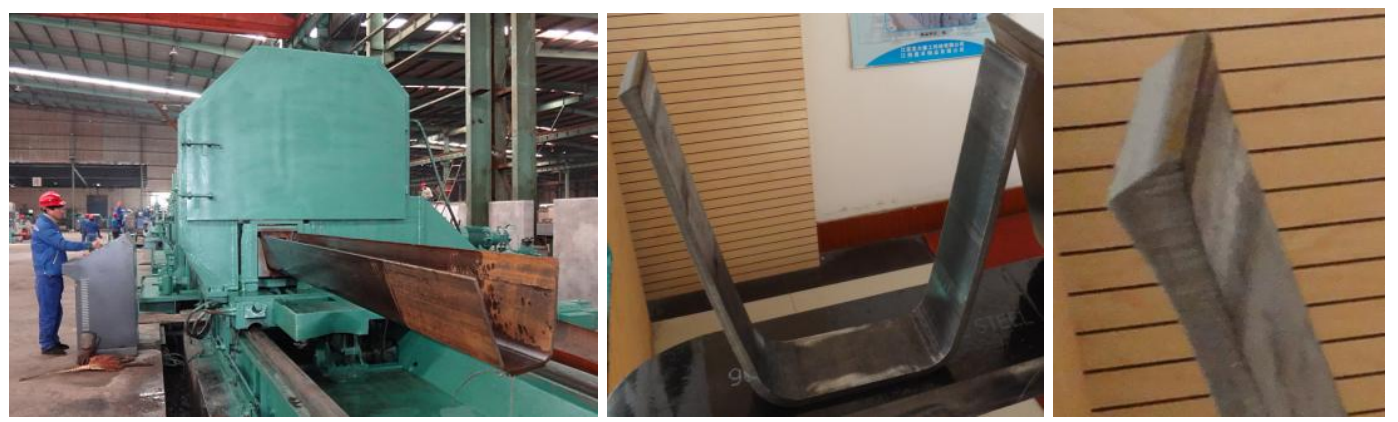

Figure 6 photos of manufacture and products for TEU

Anti-fatigue performance analysis of new TEU. For conventional U rib, when the thickness of $\mathrm{U}$ rib is $8 \mathrm{~mm}$, reserved $2 \mathrm{~mm}$ as a truncated edge, namely the weld depth is $6 \mathrm{~mm}$. According to Figure 5, the new $U$ rib set side a truncated edge keep $2 \mathrm{~mm}$, the weld depth is up to $10 \mathrm{~mm}$.

(1)assume that crack began in the weld root

Set the fatigue curve function in weld root for no thicken $\mathrm{U}$ rib is $\mathrm{N}_{1} \sigma_{1}^{m_{1}}=\mathrm{A}_{1}$, and for thicken $\mathrm{U}$ rib is $\mathrm{N}_{2} \sigma_{1}^{m_{2}}=\mathrm{A}_{2}$. Due to the fatigue structure of the two details is the same, $\mathrm{m}_{1}=\mathrm{m}_{2}=\mathrm{m}$, and the constant $\mathrm{A}_{1}=\mathrm{A}_{2}=\mathrm{A}$. then

$$
\frac{N_{2}}{N_{1}}=\left(\frac{\sigma_{1}}{\sigma_{2}}\right)^{m}
$$

Where $\mathrm{N}_{1}, \sigma_{1}, \mathrm{~m}_{1}, \mathrm{~A}_{1}=$ the number of fatigue, stress range, $\mathrm{S}-\mathrm{N}$ curve slope of negative reciprocal and weld area for no thicken $\mathrm{U}$ rib respectively; $\mathrm{N}_{2}, \sigma_{2}, \mathrm{~m}_{2}, \mathrm{~A}_{2}=$ the number of fatigue, stress range, $\mathrm{S}-\mathrm{N}$ curve slope of negative reciprocal and weld area for thicken $\mathrm{U}$ rib respectively.

For the fatigue detail of the weld connected $\mathrm{U}$ rib with deck, temporarily adopt cross weld S-N curve from tension test instead ${ }^{[20]}$ ( $\mathrm{Li}$ and Yuling 2010), $\mathrm{m}=3.2427$. According to the relationship of inversely proportional between the tensile stress and its cross-sectional area, the stress ratio of two scheme is the reciprocal of their welding depth.

By thicken edge, the increase value of fatigue life for new $U$ rib weld can be estimated by Equation (1):

$$
\frac{N_{2}}{N_{1}}=\left(\frac{\sigma_{1}}{\sigma_{2}}\right)^{m}=\left(\frac{10}{6}\right)^{3.2427}=1.666^{3.2427}=5.2
$$

From Equation (2), it can be seen that the TEU design scheme increase the thickness of U rib edge of $4 \mathrm{~mm}$, but its fatigue life is 5.2 times of the original. This estimate is in accordance with section tensile data. The follow-up studies need to refine the design scheme to ensure that the ratio of the stresses at the root of weld between no thicken $U$ rib and the TEU is greater than 1.666.

(2) assume that crack began in the base material

Although the result from the above analysis is that the new thicken $U$ rib will extend the fatigue life of 4.2 times, but fatigue crack will still appear in the welds. This paper puts forward the expectation to transfer the fatigue detail from longitudinal weld connected $U$ rib with steel bridge deck into the base material of $U$ rib. That means, making use of base material fatigue resistance is 
much higher than the characteristics of the weld to solve the fatigue cracking problems in the weld between longitudinal ribs and steel bridge deck. The ways to achieve this goal should reduce weld stress until the number to produce fatigue crack in weld is more than the number in the base material. That is:

$$
N_{2}=\frac{C_{2}}{\sigma_{2}^{m_{2}}} \geq N_{3}=\frac{C_{3}}{\sigma_{3}^{m_{3}}}
$$

Where $\mathrm{N}_{2}, \sigma_{2}, \mathrm{~m}_{2}, \mathrm{C}_{2}=$ the number of fatigue, stress range corresponding area of weld depth $\mathrm{T}_{2}$ times the length $\mathrm{L}, \mathrm{S}-\mathrm{N}$ curve slope of negative reciprocal and $\mathrm{S}-\mathrm{N}$ curve constant for new thicken $\mathrm{U}$ rib respectively; $\mathrm{N}_{3}, \sigma_{3}, \mathrm{~m}_{3}, \mathrm{~A}_{3}=$ the number of fatigue, stress range corresponding area of the $\mathrm{U}$ rid thickness $\mathrm{T}_{3}$ times the length $\mathrm{L}, \mathrm{S}-\mathrm{N}$ curve slope of negative reciprocal and $\mathrm{S}-\mathrm{N}$ curve constant for base material of $\mathrm{U}$ rib respectively.

Due to the given thought has certain conservative, $\mathrm{S}-\mathrm{N}$ curve function of base material for design is adopted $^{[21]}$ (Industry Standard 2005), while that of weld for test curve with average (Li and Yuling 2010), still using cross-section tensile test data.

For weld fatigue detail $\mathrm{m}_{2}=3.2427, \mathrm{C}_{2}=12.7261$; for base material detail $\mathrm{m}_{3}=4, \mathrm{C}_{3}=15$. Putting the parameters into the Equation (3), it can be seen that:

$$
\frac{\sigma_{3}^{m_{3}}}{\sigma_{2}^{m_{2}}} \geq \frac{15}{12.7261}=1.18
$$

For simple, put $\mathrm{m}_{2}=\mathrm{m}_{3}=\mathrm{m}$ for the load $\mathrm{P}$, and the length of the longitudinal weld is unit 1 , then the Equation (4) becomes:

$$
\frac{\sigma_{3}^{m_{3}}}{\sigma_{2}^{m_{2}}}=\frac{\frac{P^{m}}{\left(T_{3} L\right)^{m_{3}}}}{\frac{P^{m}}{\left(T_{2} L\right)^{m_{2}}}}=\frac{T_{2}^{m_{2}}}{T_{3}^{m_{3}}}=\frac{T_{2}^{3.2427}}{T_{3}^{4}} \geq 1.18
$$

Substitute $\mathrm{T}_{3}=8 \mathrm{~mm}$ into Equation (5), then

$$
T_{2} \geq \sqrt[3.242 \sqrt{1.18 T_{3}^{4}}]{1.2427} \sqrt[3.18 \times 8^{4}]{1.68 \mathrm{~mm}}
$$

Through the above analysis, if it could be further optimized, or to add the weld depth $3 \mathrm{~mm}-4 \mathrm{~mm}$ more, the weld fatigue detail is possible to be transferred to the base material. By Equation (2) to know at the case, the weld fatigue life shall be reached 15.6 times of the original. That may reach the goal not to produce fatigue crack on weld place in the first.

Above analysis are all based on the whole cross section of tensile test data. U rib longitudinal seam is actually suffered the bending. The joint of the bending fatigue strength is higher than the total cross-section of tension. However, the relative relations above are derived, not involving in the absolute value of fatigue strength, so the inference conclusion is available. But it is necessary for special fatigue test and monitoring to verify.

\section{Conclusions}

China is becoming a country with large number of steel bridge. Orthotropic steel bridge deck structure is the important components with large dosage in steel bridge (more than 2 million tons in recent years). The new orthotropic steel bridge deck structure with TEU will become the alternative 
product of traditional structure update because of its good fatigue resistance performance. The proposed new orthotropic steel bridge deck structure with TEU in this study highlight the thicken concept at the end of $U$ rib, increase welding depth between $U$ rib to the steel bridge deck, and reduce the transverse normal stress level in the weld. The suggested preliminary scheme can extend the fatigue life of 4.2 times of original structure. After further improvement it is expected to transfer the fatigue detail from the weld connection to the base material of $U$ rib so as to overcome the weld fatigue crack. It is of great significance to improve the service life of the orthotropic bridge deck.

\section{Acknowledgements}

This paper acknowledges funding support from Zhejiang Province Science and Technology Plan Projects with the number of 2014C31006.

\section{References}

[1] Inge Lyse, and Ingvald E. Madsen. (1938). "Structural Behavior of Battle-Deck Floor Systems," Proceedings of American Society of Civil Engineers, (1): 99-121.

[2] Roman Wolchuk. (1999). "Steel Orthotropic Decks Developments in the 1990s Transportation Research Record," Journal of the Transportation Research Board. No. 1688. National Academy Press. Washington D. C., 30-37.

[3] Bocchieri W J, John W. Fisher. (1998). "Williamsbirg Bridge Replacement Orthotropic Deck as Built Fatigue Test," ATLSS Report, No. 98-04.

[4] Paul A Tsakopoulos, John W. Fisher. (2005). "Full-Scale Fatigue Tests of Steel Orthotropic Deck Panel for the Bronx-Whitestone Bridge Rehabilitation," Bridge Structures, 1(1), 55-66.

[5] Paul A. Tsakopoulos, A. M. ASCE, John W. Fisher and Hon. M. ASCE. (2003). "Full-Scale Fatigue Tests of Steel Orthotropic Decks for the Williamsburg Bridge," Journal of Bridge Engineering, 8(5), 323-333.

[6] EN 1993-2. (2006). "Eurocode 3-Design of Steel Structures-Part 2: Steel Bridges," CEN, Brussels.

[7] AASHTO. (2012). AASHTO LRFD Bridge Design Specifications, Customary U.S. Units 2012, American Association of State Highway and Transportation Officials, Washington, D.C.

[8] Hyoung-Bo Sim, Chia-Ming Uang, Charles Sikorsky. (2008). "Fabrication Procedure Effects on Fatigue Resistance of Welded Joints in Steel Orthotropic Decks," International Orthotropic Bridge Conference Proceedings, August 25-30, 2008, Sacramento, California, USA.

[9] Liu Zhiguo, Li Junping, Zhang Liang, Che Ping. (2014). "Details of orthotropic steel bridge panel structure and key technology of manufacturing," Highway traffic science and technology (technology), (8), 179-182. (In Chinese).

[10]Cheng Feng. (2004). "Further Research on Mechanical Roperties of Long-Span Steel Bridge Deck Surfacing," Master thesis, Southeast University. (In Chinese).

[11]Chen Huating, Chi Xiaoqi, Huang Yan. (2012). "Comparative Analysis of Fatigue Stress in Longitudinal Rib and Cover Plate Joints of Orthotropic Steel Deck Plate," Bridge Construction, 42(6), 20-26. (In Chinese).

[12]Lei Yanni. (2011). "Analysis and Study of Efficient Calculation Width for Steel Orthotropic Decking of Steel Box Girder," Urban Roads Bridge \& Flood Control. (8), 161-163. (In Chinese).

[13]Wei Xing, Zou Xiuxing, Jiang Su, Shao Kefu. (2014). "Numerical Simulation of Residual Stress in Rib-to-TopPlate Welding of Orthotropic Steel Bridge Deck," Bridge Construction, 44(4), 27-33. (In Chinese).

[14]Cui Bing, Wu Chong, Ding Wenjun, Tong Yuqiang. (2010). "Influence of Acting Position of Vehicle Wheels on Fatigue Stress Range of Steel Deck," Journal of Architecture and Civil Engineering, 27(3), 19-23. 
[15]Tang Liang, Huang Liji, Liu Gao, Wu Wenming. (2012). "Research on Fatigue Cracks through Deck-plate in Orthotropic Steel Deck," Journal of Highway and transportation Research and Development, 29(2), 59-66. (In Chinese).

[16] Yu Bo, Qiu Hongxing, Wei Liqiang, Wang Hao, Guo Tong. (2008). "Finite element analysis on hot spot stress of orthotropic steel bridge panel," Special Structure, 25(5), 69-71,83. (In Chinese).

[17]Chen Gang, Wu Kaibin. (2013). "Experiment study on inspection of U rib fillet weld penetration in steel box girder bridge panel using ultrasonic phased array," Construction Science and Technology, (8), 96-99. (In Chinese).

[18] S R BRIGHT \& J W SMITH. (2004). “A New Design Concept for Steel Bridge Decks,” 2004 Orthotropic Bridge Conference Proceedings, August 25-27, Sacramento, California, USA

[19]Liu Xiaoguang, Zhang Yuling. (2008). "Research on fatigue calculation load and damage coefficient for multi-line railway of Dashengguan Changjiang Bridge in Nanjing," Research Report, China Academy of Railway Sciences, No. TY-2376, iron words no. 2008-0799, Mar. (In Chinese).

[20]Wang Li, Zhang Yuling. (2010). "Experimental study on the key technology for the long span railway cable-stayed bridge: Fatigue test research on the new steel welded structure," Research Report, China Academy of Railway Sciences, No. TY-2870, iron words no. 2010-0925, Oct. (In Chinese). 